\title{
Decision making of maritime development scenario on the impact of naval base for supporting navy ships operations
}

\author{
Okol Sri Suharyo $^{a^{*}}$, Ayip Rivai Prabowo ${ }^{a}$ and Eko Krisdiono ${ }^{a}$
}

${ }^{a}$ Indonesia Naval Technology College, STTAL Surabaya Indonesia

\begin{tabular}{l}
\hline C H R O N I C L E \\
\hline Article history: \\
Received May 5, 2021 \\
Received in revised format: \\
June 1, 2021 \\
Accepted August 182021 \\
Available online \\
August 18, 2021 \\
\hline Keywords: \\
Maritime Development \\
Naval Base Carrying Capacity \\
System Dynamic
\end{tabular}

\section{Introduction}

The Indonesian Navy is the spearhead in maintaining maritime security in Indonesian waters. In carrying out its main tasks, it has components of an Integrated Fleet Weapon System in which there are elements of Ships and Naval Bases. To ensure the effectiveness of the implementation of operations by the elements of the ship, ship operations are supported by the Naval Base (Naval Base) as the organizer of the support function (Ahmadi \& Herdiawan, 2019). The ability of the Navy Base to support ship operations can be measured by the percentage of Naval Base's Carrying Capacity. Naval Base's carrying capacity based on the main tasks carried out consists of 5 (five) support functions, including: (1) support for anchorage facilities; (2) support for supply facilities; (3) support for maintenance and repair facilities; (4) support facility maintenance personnel; and (5) support for base development facilities (Suharyo et al., 2017). The current condition is that Naval Base does not yet have its dock to support anchoring facilities for ship operations. To meet the support for the Naval Base anchoring facility, we collaborated with Pelindo III to use the Naval Base Harbor pier as a berth for ships. In addition to cooperation in the use of the Naval Base anchorage facility, there is also cooperation in port security, both in terms of land

\begin{abstract}
The Indonesian Navy is the spearhead in maintaining maritime security in Indonesian waters. In carrying out its main tasks, the Indonesian Navy has components of an Integrated Fleet Weapon System in which there are elements of Ships and Naval Bases. To ensure the effectiveness of carrying out operations by ship elements, ship operations are supported by the Naval Base as the
organizer of the support function. Naval Base's carrying capacity consists of 5 (five) support functions, including: (1) support for anchoring facilities; (2) support for supply facilities; (3) support for maintenance and repair facilities; (4) support facility maintenance personnel; and (5) support for base development facilities. Naval Base does not yet have its dock to support anchoring facilities for ship operations. In addition to cooperation in the use of the Naval Base anchorage facility, there is also cooperation in port security, both in terms of land and port water aspects. As the number of ship visits at Naval Base Harbor increases, the dock utility increases.
The increase in dock utility resulted in a decrease in port services which also resulted in a decrease in the Naval Base Carrying Capacity. To improve port services, Pelindo III implements the port development program contained in the Naval Base Port Master Plan in Permen KP number 792 of 2017. In this study, an analysis of the impact of the Naval Base Port development policy on the carrying capacity of the Naval Base was carried out. The data analysis uses System Dynamics modeling with a simulation period of 30 years in 3 development scenarios, namely short-term scenarios, medium-term scenarios, and long-term scenarios. From the simulation results, it is found that the construction of the Naval Base port affects the Naval Base Carrying Capacity with an average increase of $1.8 \%$ in each policy scenario. The increase in Naval Base
Carrying Capacity has an effect on increasing Ship Operations by an average of $1.8 \%$ and also increasing the Security of Naval Base Harbor by an average of $0.14 \%$. The results of the analysis of this study can be used as consideration for policymaking by the Navy.
\end{abstract}


and port water aspects. As the number of requests for ship visits at Naval Base Harbor increases, the dock utility increases. The increase in dock utility resulted in a decrease in port services which also resulted in a decrease in the Naval Base Carrying Capacity in supporting Ship Operations (Suharjo, 2019). In this study, an analysis of the impact of Naval Base Harbor development policies on the carrying capacity of the Naval Base was carried out. The data analysis uses System Dynamics modeling with a simulation period of 30 years in 3 development scenarios, namely short-term scenarios, mediumterm scenarios, and long-term scenarios. The problem statement in this study is "What is the impact of the development of the maritime sector, in this case, the development of Naval Base Harbor on the Carrying Capacity of the Naval Base on Ship Operations?" To answer these problems, several research questions can be derived as follows:

a. What variables are influential in analyzing the impact of maritime sector development in this case the revitalization of the Naval Base port on the carrying capacity of the Naval Base in supporting Ship Operations?

b. What is the impact of the port development scenario on the Naval Base Carrying Capacity in supporting ship operations?

c. What is the impact of changes in Naval Base's Carrying Capacity in cooperation to maintain stability and security of Naval Base port?

Based on the formulation of the problem, the objectives of this research are as follows:

a. Identify variables that influence in analyzing the impact of maritime sector development in this case port revitalization on the Naval Base Carrying Capacity in supporting Ship Operations.

b. Analyzing the impact of the Naval Base port development scenario on port operations and its carrying capacity for ship operations.

c. Analyzing the impact of changes in Naval Base Carrying Capacity in cooperation to maintain stability and security of the Naval Base port.

By considering several limitations of data sources and time, this research is limited to:

a. The research only discusses the construction of the Naval Base port dock which affects increasing the dock capacity and its effect on the Naval Base Carrying Capacity in supporting ship operations.

b. The research locations are the Fleet II Base area in Surabaya, Naval Base and Naval Base Harbor, and Related Agencies.

c. The developed model only applies to Naval Base ports.

d. Simulation data taken in the study began in the period 2014 to 2018.

e. The policy scenario model is based on the Indonesia Navy strength development plan at MEF 2024 and the Naval Base Port Development Master Plan contained in KP 792 in 2017.

\section{Materials and methods}

\subsection{National Development Mandate}

National development is a series of sustainable development efforts covering all aspects of the life of the community, nation, and state, to carry out the task of realizing national goals as formulated in the Preamble to the 1945 Constitution of the Republic of Indonesia. The series of development efforts contains development activities that take place in stages. , to increase the level of community welfare from generation to generation. The implementation of these efforts is carried out in the context of meeting the needs of the present without compromising the ability of future generations to meet their needs (Susilo et al., 2019; Sumantri et al., 2019). The direction of national development has been affirmed in the development white paper which is formulated towards the concept of the World Maritime Axis and explicitly in Law no. 17 of 2007 concerning the National Long-Term Development Plan for 2005-2025, which also describes the stages of the Main Priority Scale and RPJM Strategy, as follows: (1) The 1st RPJM (2005-2009) is directed at reorganizing and developing Indonesia in all areas. fields aimed at creating an Indonesia that is safe and peaceful, just and democratic, and in which the level of welfare of the people increases; (2) the 2nd RPJM (2010-2014) is aimed at further strengthening the realignment of Indonesia in all fields by emphasizing efforts to improve the quality of human resources including the development of science and technology capabilities and strengthening economic competitiveness; (3) the $3^{\text {rd }}$ RPJM (2015) -2019) is aimed at further strengthening overall development in various fields by emphasizing the achievement of competitive economic competitiveness based on the advantages of natural resources and quality human resources as well as continuously increasing science and technology capabilities; (4) The 4th RPJM (2020-2025) is aimed at realizing an independent, advanced, just and prosperous Indonesian society through accelerating development in various fields by emphasizing the establishment of a strong economic structure as the basis for developing competitive advantage in all aspects, supported by by qualified and competitive human resources (Priadi \& Tjahjono, 2015).

\subsection{Maritime Security from the point of view of the National and Military Interests}

In recent times, the creation of security at sea has become increasingly complicated and has become an object of discussion for countries all over the world on various occasions. The rise of various crimes such as sea piracy, armed robbery, and 
terrorism (maritime terrorism), as well as a Transnational Organized Crime (TOC) can disrupt the stability of security at sea which disturbs their respective national interests countries with interests in the sea. Almost all crimes that fall into the TOC category can be committed at sea or using the sea as a medium, such as illegal fishing, illicit drug trafficking, human smuggling/trafficking, and arms smuggling (Nugroho et al., 2019). Based on Law no. 34 of 2004 article 9 (b) which states that the Indonesian Navy has the task of enforcing the law and maintaining the maritime security of the national jurisdiction following the provisions of national and international law. The authority over has been stated in UNCLOS 1982 and several national laws that the area of authority applies not only in the territorial sea (12 miles) but applies to additional zone waters (24 miles), EEZ (200 miles), and even on the high seas (> 200 miles). In carrying out the main tasks of the Indonesian Navy, carrying out a maritime security operation where the shipping element is the spearhead, which is supported by the existence of a Naval Base (Naval Base) in supporting each operation that is held (Nugroho et al., 2021). The targets of Marine Security Operations are under the decision of the Chief of Staff of the Indonesian Navy number 575 of 2015 concerning the Marine Security Operations Manual, among others (Klein et al., 2009):

a. Guaranteed security and national interests at and or by sea.

b. Guaranteed shipping security as a legal consequence of the archipelagic state.

c. The creation of optimal deterrence so that in the marine area of Indonesia's national jurisdiction it is not used as an object for the interests of other countries/parties.

d. The maintenance of coordination between the Indonesian Navy and other components of the sea power that has the authority to enforce the law at sea based on the prevailing laws and regulations.

Naval Base as one of the Navy bases that have the task of providing support functions carries out five support functions which include support for anchoring facilities, support for supply facilities, support for maintenance and repair facilities, support for personnel maintenance facilities, and base coaching facilities. In carrying out the function of the Naval Base anchorage facility, it cooperates with relevant agencies (Buntoro, 2012).

\subsection{Dynamic System Modeling}

In simple terms, the system is defined as a set of sub-systems that interact with each other to achieve certain goals. In a system, each sub-system has an individual function that forms a pattern of interaction so that it can achieve certain goals. This interaction pattern will determine the structure of the system and the boundary of the system that separates the observed system from its environment (Forrester, 1968). System dynamic analysis is required in stages to be able to produce a good model of the observed system. The following are the stages carried out in dynamic system modeling (Sterman, 2000).

a. Articulation Problems. This step is to identify the key variables and concepts. This will determine the time horizon and dynamic problem characteristics to facilitate policy formulation.

b. Dynamic Hypothesis. The main task in this step is to develop a causal pie chart that explains the causal relationship between variables and convert a causal pie chart or caused and effect diagram into a stock and flow diagram.

c. Formulation. Causal loop diagrams are converted into stock and flow diagrams, such as levels, levels, and additional equations. In addition, it must consider parameters, behavioral relationships, and initial conditions.

d. Testing. The model is tested by comparing the simulated behavior of the model to the actual behavior of the system.

e. Policy Formulation and Evaluation. In the final stage, it will evaluate various policies. The interactions of different policies can also be considered, as many elements of a real system are highly interrelated.

According to Barlas (1996), in making this simulation model, the most important thing is to define the problem to be studied, determine problem boundaries and observation time horizons, and obtain variables that affect the observed system to make hypotheses about the behavior of the system being modeled. Then these variables are connected with arrows (connectors) to show a causal relationship. Then from the causal relationship that has been made, a stock and flow diagram will be made to run the model that has been created. In this stock and flow diagram, parameters or values will be entered according to real conditions. System Dynamic Modeling in this study uses the Software System Thinking Educational Learning Laboratory with Animation (STELLA), the terms are described in the following Table:

\section{Table 1}

Symbols in the System Dynamic Program (Sterman, 2000)

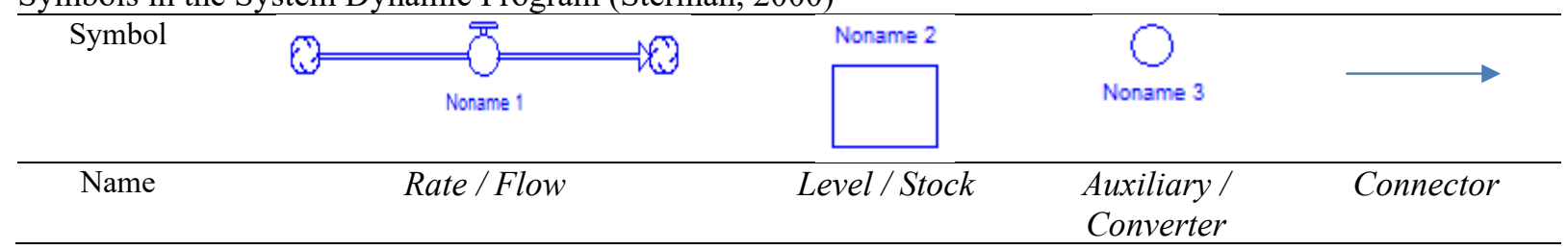


This type of model is depicted in Fig. 1. below:

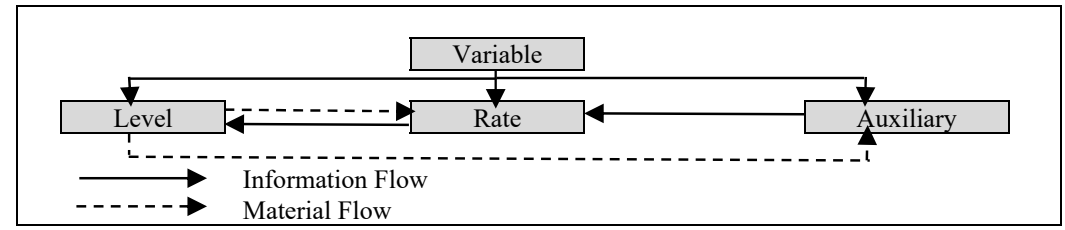

Fig. 1. Types of System Dynamic Models (Sterman, 2000)

The following is an explanation of the symbols in the System Dynamic Software:

a. Rate is the activity, movement, or flow that contributes to the change per unit time in the Level variable. Rate is the only variable that affects the Level variable. This symbol must be connected to the Level variable. The variable name is displayed at the bottom of the symbol.

b. Level is a variable that can accumulate over a while. The level variable is influenced by the Rate variable. The symbol for Level is a rectangle with the variable name listed at the top of the symbol.

c. The converter holds constant values, which define external inputs to the model, calculates algebraic relationships, and serves as a repository for graphical functions. In general, converting input to output. The name of the converter is displayed at the bottom of the symbol.

d. This connector is used to connect the various elements of the model. Connections can be between Level, between Converter, Rate to Converter, Converter to Rate, and Level to Converter.

\subsection{Research method}

Several approaches that are often used in research are qualitative, quantitative approaches, and a combination of the two approaches. This study using a quantitative approach. Where in the dynamic system modeling the development and model development is carried out by mathematically formulating the relationship between research variables according to stocks and flows (model structure specifications and decision rules). The stages of research in this study were carried out in several stages, namely the identification of variables and conceptualization of the model, the model simulation stage, as well as analysis and concluding. A literature review or literature study is carried out as a theoretical basis for research. The literature study is carried out in the form of an assessment by collecting information from various library sources, both in the form of books, journals, articles, dissertations, as well as previous research on national development in the maritime sector, the influence of an agency's operational activities on other activities in a particular area or another work unit as well as research related to system dynamics. In addition, a field study was also conducted to determine the actual condition of the system (Britt, 2014). The stages of variable identification and model conceptualization are the initial stages of introducing the entire system to be modeled in the study. This stage is carried out to obtain what variables and parameters will be used in the modeling by conducting a literature study and conducting interviews with several experts. This stage begins with identifying variables from the entire system, then composes the concept of the relationship between the main variables followed by the conceptualization stage of the model by making Causal Loops Diagrams (CLD) which show causal relationships and interrelationships between variables, to represent the entire system identified. In the next stage, model simulation is carried out with the simulation model formulation stage, running the initial simulation model. The formulation of the simulation model is based on the conceptualization of the initial model that has been made, then mathematically formulated the relationships between these variables according to stocks and flows (model structure specifications and decision rules). At this stage, model testing is also carried out, there are 3 steps carried out, namely model simulation, model verification, and model validation. The running model is done by running the initial simulation model (Buzan, 1983). The application of policy scenarios is carried out to analyze the effect of port development on the carrying capacity of the Naval Base from the model that has been made. At this stage, it is done by changing the port capacity according to the port development plan, implementation time, and or development of the model so that different outputs will be produced from the initial (existing) conditions. From the simulation results of model development, then it is compared with the existing output, and identification is made whether it produces a significant change or not.

\section{Results and discussion}

\subsection{Naval Base Port Development Plan}

The existing condition of the Naval Base port has 3 moorings at the East Pier which are intended to support the services of Cargo Ships, Passenger Ships, and support the Operations of the Ship element. While at the south pier there is 1 mooring dock which is fully used to support LNG ships and 1 jetty as a liquid bulk dock. 


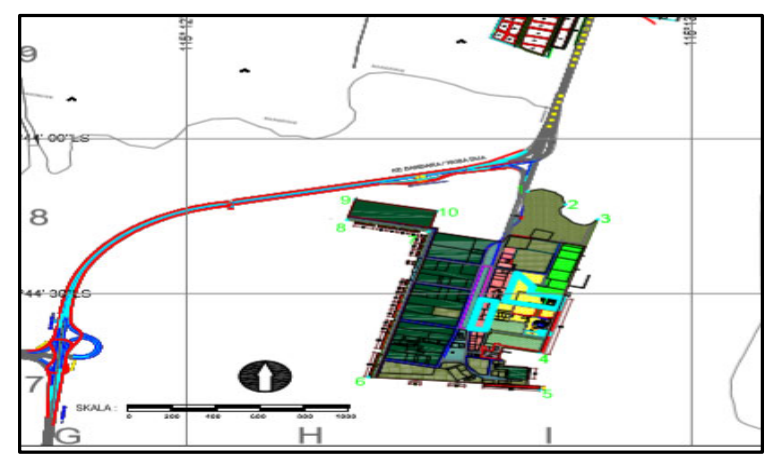

Fig. 2. Existing Condition of Naval Base Harbor

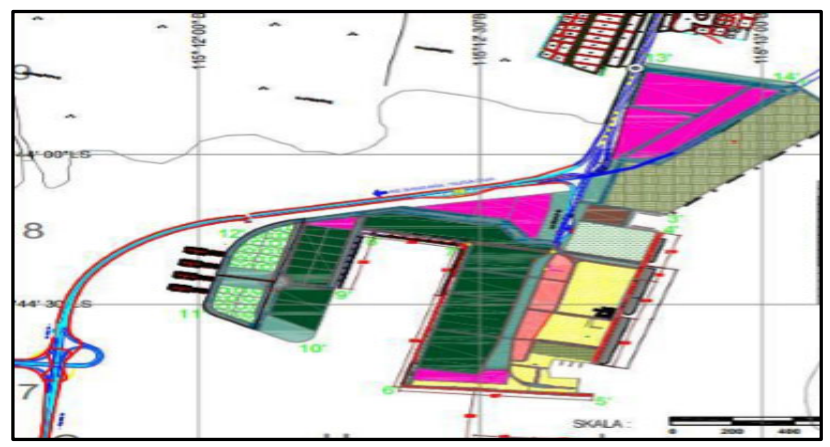

Fig. 3. Naval Base Harbor Masterplan

Based on the Naval Base Port Master Plan (Naval Base PMP) as stated in the ministerial regulation KP 792 of 2017 , the development of the Naval Base port is divided into 3 stages, namely: (1) Short Term Phase (2017-2022); Medium Term Stage (2017-2027); and the Long-Term Stage (2017-2032). The allocation for port development is adjusted to the National Spatial Planning and City Spatial Planning. With the Final Conditions, it is expected that Naval Base Port has 1 (one) special wharf for state ships, 5 (five) mooring docks (3 (three) moorings at the East Pier, and 2 (two) moorings at the South Pier) as well as the relocation of liquid and gas bulk jetty at to the north of 3 moorings.

\subsection{Naval Base Carrying Capacity}

The value of Naval Base's Carrying Capacity is related to Naval Base's ability to support every operating ship, both related to operations and only re-stocking for the readiness of the ship to continue the operations carried out The assessment is carried out by measuring the percentage of Naval Base's ability to fulfill Naval Base's operational requirements in its service to ships. The following is the Naval Base Carrying Capacity index which is the result of field studies and brainstorming with experts. As shown in Table 2 as follows,

Table 2

Naval Base Carrying Capacity Index

\begin{tabular}{ccc}
\hline No & Naval Base Carrying Capacity & Index Conversion \\
\hline 1 & Not capable & $0.00-0.20$ \\
2 & Less capable & $0.21-0.40$ \\
3 & Enough capable & $0.41-0.60$ \\
4 & Capable & $0.61-0.80$ \\
5 & Very Capable & $0.81-1.00$ \\
\hline
\end{tabular}

The weighting of the Naval Base Supporting Capacity sub-variable on the Expert Choice shows the results that show the priority weight for each of the Naval Base support function variables. Whereas the supply function is a support function with the highest priority scale (0.359), while the anchoring facility is the second priority with a value of 0.333 . This shows that the two functions are the main functions of Naval Base Carrying Capacity for ship operations, while the other three functions are not the main priority. The inconsistency value of 0.04 or $4 \%$ indicates that the data from the questionnaire to several experts is consistent.

\subsection{Naval Base Harbor Activities}

Naval Base Port is a public port under the Pelindo III Nusra branch. This port serves the activities of various types of ships, both cargo, passenger, liquid bulk tankers, gas tankers, warships, and various other types of ships. Details of ship visits at Naval Base Pier within a period of 5 (five) years for the 2014-2018 period are presented Table 3 as follows,

Table 3

Ship Visits at Naval Base Harbor

\begin{tabular}{cccccccccc}
\hline No & Years & General Cargo & Container & Fuel & LNG & Cruise & PELNI & Navy Ships & Others \\
\hline 1 & 2014 & 10 & 55 & 179 & 20 & 72 & 610 & 49 \\
2 & 2015 & 11 & 53 & 184 & 22 & 74 & 608 & 55 \\
3 & 2016 & 11 & 56 & 180 & 24 & 75 & 610 & 40 \\
4 & 2017 & 12 & 55 & 185 & 23 & 79 & 618 & 32 \\
5 & 2018 & 12 & 57 & 182 & 25 & 81 & 615 & 33 \\
\hline
\end{tabular}

According to Table 3, it can be seen that there is an increase in the number of requests for ship visits per year. The increase in demand for ship visits that affect Ship Operational support is directly affected by the increase in visits from cruise ships, PELNI ships, and Cargo. General Cargo ship visits experienced an average increase of $4.7 \%$, Containers experienced an average increase of $0.9 \%$, BBM ships experienced an average increase of $0.4 \%$, LNG ships experienced an average increase 
of $5.9 \%$, ships cruises experienced an increase of $2.9 \%$ and PELNI ships experienced an average increase of $0.2 \%$. An increase in the demand for ship visits that is not accompanied by an increase in the capacity of the pier directly increases the port's utility.

\subsection{Navy Ships Operations}

Based on data from the Navy Base Kesyahbandaran Service, the average operational mobility of ships in and out of the Naval Base Harbor area is 49 ship elements each year. The number of Vessel Operational mobility is taken from the Vessel departure data / Transport Time (WA), data returning from the operating area / Arrival Time (WD). In detail, the number of ship visits at Naval Base port is presented in Table 4 as follows,

Table 4

Ship Operations at Naval Base Harbor

\begin{tabular}{cccccc}
\hline & Years & WA & WD & Fleet Element & Other Main Command Elements \\
\hline 1 & 2014 & 49 & 49 & 44 & 5 \\
2 & 2015 & 55 & 55 & 49 & 6 \\
3 & 2016 & 40 & 40 & 38 & 2 \\
4 & 2017 & 32 & 32 & 30 & 2 \\
5 & 2018 & 33 & 33 & 31 & 2 \\
\hline
\end{tabular}

The number of ship elements docked at the Naval Base Harbor pier supported by the Lane is more influenced by the number of ship element operations degrees from Fleet Element. There are 92.6\% of the ships that dock at Naval Base Pier are elements of the operation degree from Fleet II, while $7.4 \%$ are elements of other cities.

\subsection{Port Security}

The port is a vital object for the state. Therefore, Port Security is very important to be maintained to provide security for all activities that occur in the port. Moreover, Naval Base Harbor which is the entrance for foreign tourists by sea, port security is used as an initial reference as a security assessment in Indonesia. The port security assessment has 2 aspects of threat assessment, namely threats on land and threats in the waters of the port area. The two important parts of the port must be monitored continuously to achieve security stability. The forms of threats on the ground can be in the form of theft, robbery, destruction of facilities, sabotage, smuggling, and fraud, harassment of visitors, fire, and administrative violations. While the forms of threats from the marine aspect can be in the form of theft, destruction of channel facilities, piracy, smuggling, people falling at sea, fires, leaks, accidents on water games, ship collisions, and administrative violations. Determination of the port security value index is carried out by field studies and brainstorming with experts. The Port Security Index is structured in Table 5 as follows:

Table 5

Port Security Index

\begin{tabular}{cccc}
\hline No & Port Security Condition & Index Conversion & Mean \\
\hline 1 & Danger & $0.0-0.2$ & Not safe \\
2 & Warning & $0.21-0.4$ & Less Safe \\
3 & Alert & $0.41-0.6$ & Safe Enough \\
4 & Safe & $0.61-0.8$ & Secure \\
5 & Conducive & $0.81-1.00$ & Very safe \\
\hline
\end{tabular}

Based on data for the last 5 years, there have been several incidents related to port security at Naval Base port, including ship running aground, theft of visitors, people falling in the sea around the turning basin pool, ship fire at the dock, ship leaks at the dock and accidents on water games in the harbor channel. The details are presented in Table 6 as follows:

Table 6

Naval Base Port Security Assessment

\begin{tabular}{|c|c|c|c|c|c|c|}
\hline \multirow[t]{2}{*}{ No } & \multirow[t]{2}{*}{ Incident } & \multicolumn{5}{|c|}{ Years } \\
\hline & & 2014 & 2015 & 2016 & 2017 & 2018 \\
\hline 1. & Theft on the Ground & 1 & - & - & - & - \\
\hline 2. & People Fall In The Sea & 1 & 1 & 2 & 1 & 1 \\
\hline 3. & Fire & - & 1 & - & 1 & 1 \\
\hline 4. & Leakage & - & 1 & - & - & - \\
\hline 5. & Ship Aground & 1 & - & - & - & - \\
\hline 6. & Ride Accident & 1 & - & 1 & 1 & - \\
\hline \multicolumn{2}{|c|}{ Conversion } & 0.67 & 0.64 & 0.67 & 0.65 & 0.70 \\
\hline \multicolumn{2}{|c|}{ Assessment } & Safe & Safe & Safe & Safe & Safe \\
\hline
\end{tabular}




\subsection{Causal Loop Diagram (CLD)}

The Causal Loop Diagram illustrates the causal relationship of each related variable. The relationship between variables is depicted by the converter line. The red line with the sign $(+)$ means the variable has a positive effect on other variables, while the blue line with the sign (-) describes the negative relationship of a variable with other variables. Variable relationships form positive and negative loops as shown in Fig. 4.

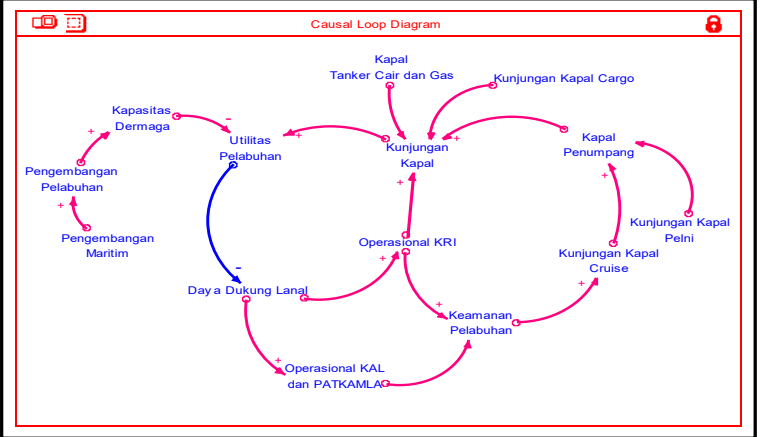

Fig. 4. Causal Loop Diagram of Research

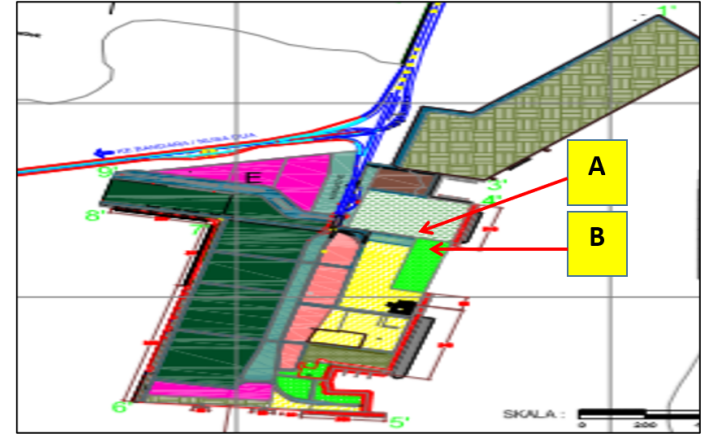

Fig. 5. Planned Allocation of Wharf Development in Short Term (2017-2022)

\subsection{Policy Scenario}

The formulation of the policy scenario is based on the 2017 Naval Base Harbor RIP which divides the development stages into 3 (three) stages, namely the Short Term, Medium Term, and Long Term Phase.

\section{a. Short Term Scenario (2017-2022)}

In the short-term development scenario, it is planned to be completed in 2022. Several development plans are being implemented including the construction of a $110 \mathrm{~m}$ long state ship dock, construction of a $210 \mathrm{~m}$ container dock, and an extension of a $60 \mathrm{~m}$ cruise pier north of the East Pier. In this scenario, it resulted in the addition of 1 multipurpose mooring dock. The Allocation Plan Drawing shows the allocation of the wharf to be built in the short-term plan, where (A) is a state ship dock and (B) is a multipurpose dock.

b. Medium Term Scenario (2017-2027)

In the Medium-Term Scenario (2017-2027) there is a $234 \mathrm{~m}$ cruise pier construction program north of the East Pier and an extension of the South Pier to the west along $210 \mathrm{~m}$ in ex. Liquid bulk jetty as a Passenger Pier and construction of 2 jetty units in the liquid and gas bulk zone. The allocation for the construction of the wharf can be seen in the following figure. Additional 2 jetty units in the Liquid and Gas Bulk Zone (C), 1 Cruise mooring at East Pier (D), and 1 passenger boat mooring at South Pier (E).

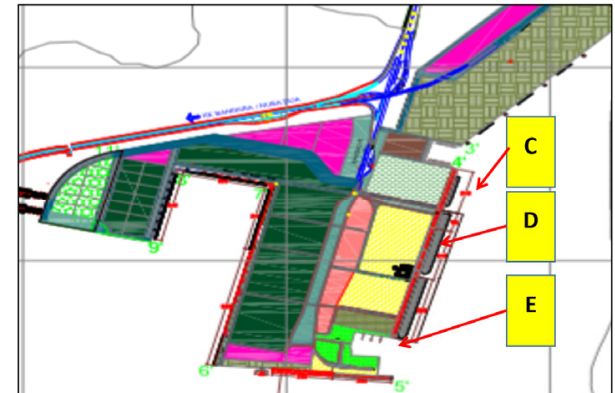

Fig. 6. Planned Allocation of Wharf Development in Medium Term (2017-2027)

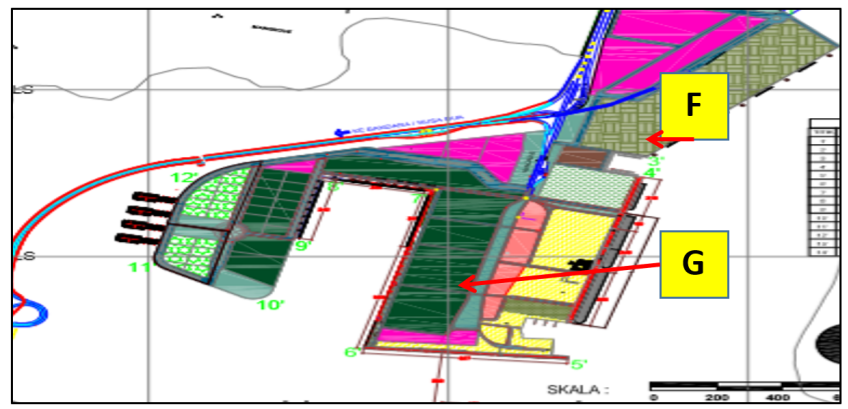

Fig. 7. Allocation Plan for Wharf Development in Long Term (2017-2032)

\section{c. Long Term Scenario (2017-2037)}

In the Long-Term Scenario (2017-2037) there is a plan to add 1 jetty unit in the liquid and gas bulk zone and an extension of the South Pier to the west for $211 \mathrm{~m}$ in ex. Liquid bulk jetty as Passenger Pier. The allocation for the construction of the wharf is shown in the figure, the addition of 1 jetty mooring unit in the liquid and gas bulk zone (F), and the extension of the South Pier $(\mathrm{G})$. 


\subsection{Policy Scenario Analysis}

Comparison of the simulation results between the existing conditions and the three scenarios, there is an average change in dock utility, Naval Base Carrying Capacity, number of ship operations, and the level of security of the Naval Base port. In detail, it can be seen in the following table of simulation results:

Table 7

Policy Scenario Simulation Results

\begin{tabular}{|c|c|c|c|c|c|}
\hline \multirow[b]{3}{*}{ No } & \multirow[b]{3}{*}{ Variable } & \multicolumn{4}{|c|}{ Average Simulation Results } \\
\hline & & \multicolumn{4}{|c|}{ Scenario } \\
\hline & & Existing & Short Term & Medium Term & Short Term \\
\hline 1 & Naval Base Carrying Capacity & 0.635 & 0.654 & 0.670 & 0.672 \\
\hline 2 & Wharf Utility & 0.589 & 0.580 & 0.467 & 0.453 \\
\hline 3 & Ship Operation & 36.00 & 37.00 & 38.00 & 38.00 \\
\hline 4 & Port Security & 0.686 & 0.687 & 0.688 & 0.689 \\
\hline
\end{tabular}

\section{Research Implication}

As the implementing elements of the support function for the deployment of the Navy's fleet, Naval Base is expected to have optimal carrying capacity in supporting ship operations. From the analysis of the data and facts in this study, it was found that the Naval Base depended on the condition of the Naval Base port. The Naval Base Carrying Capacity Index in supporting Ship Operations has decreased in line with the increase in port utilities. From the results of the study, it was also found that there was a decrease in the Naval Base Carrying Capacity Index which was influenced by the ability of Logistics support (0.358) by Naval Base faced with government policies listed in the Minister of Energy and Mineral Resources Regulation No. 41 of 2018 where the services of PT. Pertamina in the region, especially in Naval Base Harbor, does not serve the need for diesel fuel to be replaced with biodiesel-type fuel. To achieve the expected condition of the Naval Base Carrying Capacity Index, the Navy institution can consider the independence of anchoring facilities by building port facilities operated by the Naval Base. This is in line with the concept of the Indonesian Navy's MEF Development in improving the facilities and infrastructure that support the operation of the defense equipment and its crew in realizing the deployment of more effective operational elements, as well as the need for gradual policy development regarding the development of adaptive technology for the Indonesian Navy elements to adjust the fulfillment fuel needs with government policies.

\section{Conclusion}

The conclusions that can be drawn are:

a. Based on the results of this study, it can be concluded that the influential variable in analyzing the impact of maritime sector development on the carrying capacity of the Naval Base in supporting ship operations is the dock utility which is strongly influenced by the addition of dock capacity.

b. Based on the analysis of the simulation results of the dynamic system model in this study, it can be concluded that the port development scenario as stated in the Naval Base Harbor Master Plan (RIP) can increase the carrying capacity of the Naval Base in supporting ship operations.

c. Based on the analysis of the simulation results of the dynamic system model in this study, it can be concluded that the Naval Base plays an active role in cooperation in maintaining the stability of the security of the Naval Base port by involving Naval Base personnel to secure the port on the land aspect and carrying out the operation of elements of the maritime security patrol to secure the port waters. Increasing the Naval Base Carrying Capacity in supporting ship operations also has an impact on increasing port security.

\section{Future work}

In the final stage of the research, several suggestions can be given for further research, namely:

a. Further research can examine the impact of the policy of applying B20 fuel which is included in the Fasbekal variable which also affects the carrying capacity of the Naval Base.

b. Further research can examine the impact of the development of the maritime sector on the island of Indonesia on the condition of maritime security in the Indonesia Strait.

c. To consider the construction of the Anchorage Facility which is operated by the Navy Naval Base so as not to interfere with port activities, especially the public dock at Naval Base Harbor.

d. To be able to consider the ideal Navy dock location as one of the factors that can directly affect the effectiveness of support by Naval Base in supporting ship operations

e. This simulation is adaptable and updateable, can adjust to the latest updated conditions. 


\section{Acknowledgment}

The authors greatly acknowledge the support from Indonesia Naval Technology College STTAL Surabaya Indonesia for providing the necessary resources to carry out this research work. The authors are also grateful to the anonymous reviewers and journal editorial board for their many insightful comments, which have significantly improved this article.

\section{References}

Ahmadi, A., \& Herdiawan, D. (2021). The implementation of Borda and Promethee for decision making of naval base selection. Decision Science Letters, 10(2), 129-138.

Anwar, S. (2018). Membangun keamanan maritim Indonesia dalam analisa kepentingan, ancaman, dan kekuatan laut. Jurnal Pertahanan \& Bela Negara, 6(3), 69-90.

Bachtiar, A., Marimin, M., Adrianto, L., \& Bura, R. (2021). Determinants of shipbuilding industry competitive factors and institutional model analysis. Decision Science Letters, 10(2), 151-162.

Barlas, Y. (1996). Formal aspects of model validity and validation in system dynamics. System Dynamics Review: The Journal of the System Dynamics Society, 12(3), 183-210.

Britt, D. W. (2014). A conceptual introduction to modeling: Qualitative and quantitative perspectives. Psychology Press.

Buntoro, K. (2012). Alur laut kepulauan Indonesia (ALKI): prospek dan kendala. Sekolah Staf dan Komando TNI AL (Seskoal).

Buzan, B. (1983). People, States and Fear; The National Secutity Problem in International Relation. The University of North Carolina Press.

Forrester, J. W. (1968). Principle of System. Massachusetts: Wright.

Klein, N., Mossop, J., \& Rothwell, D. R. (Eds.). (2009). Maritime security: international law and policy perspectives from Australia and New Zealand. Routledge.

Nugroho, S., Bandono, A., \& Suharyo, O. (2021). Human resources development assessment planning program and bureaucratic reform management on the performance of government organization. Management Science Letters, 11(4), 1429-1438.

Nugroho, S. H., Madhakomala, R., \& Gunawan, K. (2019). The system dynamic model for policy evaluation of navy personnel on the state-duty aspect. International Journal of Scientific and Technology Research, 8(12), 228-236.

Priadi, A. A., \& Tjahjono, T. (2015). Implementation of traffic separation scheme for preventing accidents on the Sunda Strait. International Journal of Technology, 6(6), 990-997.

Sterman, J. D. (2000). Business dynamics: System thinking and modeling for a complex world Irwin McGrawHill. Massachusetts Institute of Technology, Engineering Systems Division: Cambridge, MA, USA.

Susilo, A. K., Ciptomulyono, U., Putra, I. N., Ahmadi, A., \& Suharyo, O. S. (2019). Navy Ability Development Strategy using SWOT Analysis-Interpretative Structural Modeling (ISM). Strategic Management-International Journal of Strategic Management and Decision Support Systems in Strategic Management, 24(1).

Suharjo, B. (2019). Using System Dynamics to Analyze the Leadership Style on Motivation and Soldier's Performance. In E3S Web of Conferences (Vol. 125, p. 22002). EDP Sciences.

Suharyo, O. S., Manfaat, D., \& Armono, H. D. (2017). Establishing the location of naval base using fuzzy MCDM and covering technique methods: A case study. International Journal of Operations and Quantitative Management, IJOQM, 23(1), 61-87.

Sumantri, S. H., Bastari, A., \& Sri Suharyo, O. (2019). The assessment of naval base sustainability using a dynamic system thinking approach. International Journal of Scientific and Technology Research, 8(11), 388-394. 


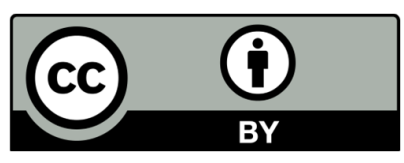

(C) 2022 by the authors; licensee Growing Science, Canada. This is an open access article distributed under the terms and conditions of the Creative Commons Attribution (CC-BY) license (http://creativecommons.org/licenses/by/4.0/). 